\title{
La teatralidad novohispana vista desde los acontecimientos históricos. Del virreinato a la independencia
}

\section{The Theatricality of New Spain seen from Historical Events. From the Viceroyalty to Independence}

\section{Isabel Sainz Bariain}

Universidad de La Rioja

ESPAÑA

isabel.sainzb@unirioja.es

[Hipogrifo, (issn: 2328-1308), 8.2, 2020, pp. 373-386]

Recibido: 21-05-2020 / Aceptado: 07-08-2020

DOI: http://dx.doi.org/10.13035/H.2020.08.02.23

Resumen. Este trabajo pretende observar algunos de los cambios más significativos en la teatralidad mexicana desde la época virreinal hasta la independencia. Para ello, recorreremos los aspectos más significativos del teatro novohispano, partiendo de su relación con el contexto histórico. Analizaremos algunas teorías sobre la repercusión del género en la época colonial, para poder comprender con mayor exactitud el alcance real de la bibliografía barroca de la Nueva España. En plena colonia, pero ya en el siglo XVIII, podemos apreciar cómo va evolucionando el teatro movido por el cambio de mentalidad que se va gestando en la sociedad novohispana. Finalmente, observaremos cómo cambió el teatro durante la revolución por la Independencia y tras conseguirla, ya que se verá cómo la teatralidad de la sociedad también da un gran cambio respecto a lo anterior.

Palabras clave. Teatro; transformación; época colonial; Independencia; México.

Abstract. This work tries to observe the most significant changes in the Mexican theatricality from the viceregal era to independence. To this effect, we will go through the most important aspects of New Spanish theater, starting from its relationship with the historical context. We will analyze some theories about the repercussion of genre in colonial times, in order to understand more precisely the 
real scope of the Baroque bibliography of New Spain. During the colonial era, but already in the eighteenth century we can see how the theater evolves, moved by the change of mentality that is brewing in New Spanish society. Finally, we will observe how the theater changed both, during the revolution for independence and after achieving it, and it will be seen how the theatricality of society also experienced a major change with regard to earlier years.

Keywords. Theater; Transformation; Colonial era; Independence, Mexico.

\section{INTRODUCCIÓN}

Este trabajo va a consistir en revisar la evolución del teatro novohispano desde la época colonial hasta la independencia mexicana teniendo en cuenta el devenir histórico y cómo afecta a la literatura. De esta forma, se hará un repaso al teatro durante los siglos que duró el virreinato y cómo cambia tras circunstancias históricas de tan alto impacto para la sociedad y su cultura. Repasar la historia de México permite valorar el presente. La bibliografía sobre el proceso de independencia es verdaderamente abrumadora, lo que demuestra el enorme interés que suscita entre los intelectuales. Se trata de un número inabarcable de textos centrados en el análisis histórico y político. En esta ocasión, se seleccionarán los datos más relevantes para comprender el cambio de mentalidad ${ }^{7}$ y su reflejo en la literatura. En suma, es importante tener en cuenta que este gran proceso de independencia suscitó grandes cambios que quedaron marcados en el papel de la literatura.

El cambio de mentalidad se produce, como es de esperar, durante el virreinato. Fue desde finales del siglo XVIII cuando «ciertos grupos de criollos propagaron una corriente de pensamiento que reivindicaba el derecho de los americanos a ocupar cargos políticos y a encabezar los gobiernos locales; esto fue su respuesta a las reformas implementadas por los Borbones que los alejaba de la práctica política»². Como es lógico, esta decisión provocó que la enemistad entre criollos y españoles se pronunciara, por lo que tenemos varios episodios de violencia contra este último grupo. No obstante, estos episodios no solo afectaron a los españoles, sino todo aquello que participara de lo españo/3. La sociedad novohispana se había forjado durante los tres siglos que duró el virreinato. Un mestizaje cultural que permitió la asimilación de muchos rasgos de la cultura hispánica en el Nuevo Mundo 4 , pero algunos derechos de los que gozaban los grupos del poder, formados por españoles, no alcanzaron a toda la sociedad. En otras palabras:

\footnotetext{
1. Para un mejor conocimiento de la Historia de México ver Gruzinski, 2004; Ortiz Escamilla, 2008.

2. Bernal Ruiz, 2007, p. 10.

3. Para profundizar sobre el concepto de lo español y los problemas entre criollos y españoles remito al trabajo mencionado de Bernal Ruiz, 2007. Queda claro que ya en pleno siglo XVIII se va gestando el problema político que acabará con la revolución por la independencia (1810-1821).

4. Sobre el proceso de transculturación ver Ortiz, 1983, pp. 86-90.
} 
Se trataba de una sociedad mestiza, racial y culturalmente, sus integrantes habían adoptado elementos hispanos, como la religión, las festividades, aspectos culinarios, y prácticas que les permitían funcionar en esa dinámica y que, de alguna manera, concebían como parte de su cultura. Sin embargo, había otros elementos, derechos y prácticas hispanas de las que estaban excluidos y que, asociados a quienes se decían españoles - ya fuesen peninsulares o americanos- eran vistos como un mundo aparte ${ }^{5}$.

Está claro que esta sociedad, producto del mestizaje, estaba configurada según jerarquías de casta y se mantenía gracias a complejas estructuras sociales marcadas por la autoridad del virrey, pero ante el cambio de mentalidad que también impregna Europa, no era de extrañar que el sentir de todas esas castas fuera evolucionando poco a poco hacia otro sistema social. Fueron varias causas políticas externas al virreinato que influyeron en este proceso: la Revolución Industrial, la Revolución Francesa, la Independencia de Estados Unidos y la invasión francesa de España. Todos estos eventos provocaron considerables cambios en la percepción del poder y la autoridad en el virreinato novohispano. La Revolución Industrial abrió la economía y cambió el orden jerárquico de las clases sociales. Esto permitió que ideas de liberalismo económico llegasen también a Nueva España. Por otro lado, el ascenso social de la burguesía se debió en gran medida a los ideales de la Revolución Francesa. Napoleón, por su parte, deseó controlar Europa. Como se sabe, quiso debilitar la economía inglesa, pero Portugal se desbancó de sus deseos provocando la entrada de las tropas napoleónicas a la Península. Así fue como se produjo la invasión francesa en España. Este hecho afectó especialmente al virreinato, pues pudo observar la debilidad de la monarquía hispánica. Está claro que la Independencia de Estados Unidos pudo servir de ejemplo para sus vecinos, y este era uno de los grandes miedos de los políticos españoles.

Todos estos hechos históricos sumados a los propios cambios que estaba viviendo la colonia produjeron la ruptura definitiva. La circunstancia más significativa vino dada por la lucha de poder entre los españoles arraigados en el virreinato y los criollos, como señalaba con anterioridad. En realidad, a partir de 1810 se sintió la necesidad de reformar la sociedad, de ahí el estallido a partir de septiembre de ese año tras la misa del cura Hidalgo ${ }^{6}$. «El manifiesto se resumía en la lucha por la independencia, la defensa de la monarquía, de la religión católica y de la virgen de Guadalupe. A pesar del registro tradicional que expresaba el movimiento, la presencia de peones rurales, mineros y campesinos junto a la introducción del reclamo agrario dotaron a la revuelta de un contenido desestabilizador del mismo orden que pretendían conservar»? ${ }^{7}$. Parece ser que las élites criollas dieron un giro sustancial al movimiento, ya que

construyeron una representación de sí mismas como clases dirigentes y en el contexto de la crisis de sucesión su actitud fue creativamente ambigua, oscilando en función de los tiempos que imponía el conflicto europeo y en relación a

5. Bernal Ruiz, 2007, p. 11

6. Ver Bernal Ruiz, 2007; Gentile, 2010.

7. Gentile, 2010, p. 75. 
la propia capacidad de consensuar o imponer la autoridad y legitimidad de las Juntas de Gobierno en sus respectivas áreas de influencia. La heterogeneidad de quienes formaban parte de la élite se mostró no solo en relación a las ocupaciones específicas de cada grupo -comerciantes, hacendados, funcionarios, etc. - sino también en las distintas alternativas planteadas frente a la independencia ${ }^{8}$.

Existían dos vertientes en este conflicto; por un lado, quienes ante la invasión francesa de España temían que las colonias también pasasen a manos extranjeras. Esta postura defendía la necesidad de proteger la fe católica. Pero a todo ello, se suma otra idea, que es la necesidad de romper el vínculo colonial precisamente para poder salvarla. No debemos olvidar que «la fe católica constituía una de las mayores cosmovisiones con fuerza identitaria suficiente para unificar una población dividida por castas y estamentos»9. Con todo, a esta idea de protección, añadimos los problemas económicos arrastrados y, sobre todo, los políticos, en los que se agrava el binomio criollo / peninsular. Si bien es cierto que el movimiento iniciado por Hidalgo tuvo dentro del sector criollo detractores, pues muchos pensaron que sería mejor permanecer vinculados a la metrópoli10. Más adelante sí romperían con todo, pero por el momento reclamaban una reforma que les permitiera gozar de los derechos políticos que tenían los peninsulares ${ }^{11}$.

Una de las herramientas más potentes en este movimiento fue la prensa. Tanto para quienes defendían la permanencia a la colonia, como quienes lucharon por la independencia. La prensa juega un papel fundamental en todo este cambio social, al igual que ocurre en Europa, ya que los periódicos difunden los nuevos ideales. Por ejemplo, para Jean Franco, el Diario de México, fundado y editado por Carlos María Bustamante (1805) «puede considerarse representativo de la nueva forma de expresión cuya novedad consistía precisamente en la yuxtaposición de tipos de discurso heterogéneos que abarcaba sermones, ensayos, noticias y anuncios comerciales» ${ }^{12}$. La prensa fue fundamental tanto para el nuevo pensador americano, como por ejemplo Lizardi ${ }^{3}$, un nuevo hombre de letras ${ }^{14}$, como para quien todavía deseaba mantener el orden social establecido, como se ve reflejado en las siguientes palabras de Pedro del Rivero, vocal secretario de la Junta de Sevilla, quien se dirige al virrey por la campaña de España contra los franceses:

8. Gentile, 2010, p. 75

9. Gentile, 2010, p. 79.

10. Sobre las distintas posturas que generaron las palabras de Hidalgo, así como para entender la violencia generada en ambas posturas, recomiendo la lectura de Landavazo, 2008. El autor se acerca a este período histórico desde un enfoque global, evitando posicionarse, problema que ha detectado en muchos de los trabajos sobre el proceso de independencia en México.

11. Bernal Ruiz, 2007, p. 10. A los peninsulares o españoles se les proclamó de manera peyorativa como gachupines, término que aparece en innumerables escritos de esta época.

12. Franco, 1986, p. 22.

13. Ver Franco, 1986.

14. Insúa, 2011, p. 159. 
El gobierno, con franqueza y verdad digna de un pueblo, ha anunciado por medio de sus gacetas los sucesos prósperos y adversos de nuestras armas, porque no trata de adormecerle sobre los peligros de la patria, ni de halagarle con esperanzas lisonjeras en el momento en que nuevos riesgos exigen nuevos sacrificios, y nuevos males mayor constancia. Esta misma conducta que ha observado respecto de la Península, es justo que guarde respecto de sus fieles pueblos de la América, los cuales no por más distantes están menos unidos a la causa sagrada que defendemos ni por más seguros, menos interesados en la suerte de sus hermanos de Europa ${ }^{15}$.

Como vemos, es muy significativo el papel que se le concede a la prensa tanto en la Península como en los territorios americanos. Insúa señala cómo la prensa «pasa a constituir un naciente tipo de literatura que se brinda al servició del público, que quiere ser "útil", pero que también considera a la masa lectora como su nuevo mecenas» ${ }^{16}$. Se entiende que el periodismo se convierte en un nuevo y valioso instrumento político, por lo que podemos observar con nitidez las posturas de cada uno de los bandos. Para Gentile, la prensa «constituyó un instrumento de confrontación y un espacio público en tanto la discusión de toda clase de temas, entre ellos los políticos, comenzó a desvincularse del control ejercido por el Estado absolutista» ${ }^{17}$. Es más, apunta que el control de la información, así como de la difusión pudo implicar una serie de funciones para designar en el plano simbólico al enemigo y legitimar un orden político específico ${ }^{18}$.

Es lógico extrapolar este papel tan primordial a las letras, en general. De esta manera, la literatura también cobró un significado nuevo que reflejó todos estos cambios mencionados. Un momento histórico de gran relevancia que arrasa en todas las manifestaciones culturales, sociales y políticas al mismo tiempo. Veremos cómo afecta al teatro, por lo que es necesario recordar cómo era la percepción del teatro y de la teatralidad durante la época colonial, para así poder comprender mejor qué supone el impacto de los acontecimientos de la revolución por la independencia en la gestación del teatro ya en pleno siglo XIX.

\section{TEATRO EN LA ÉPOCA COLONIAL}

La literatura es producto de una realidad histórica y, por tanto, podemos considerarla como un reflejo del contexto en que se produce. Todos los cambios que hemos mencionado van a verse representados de un modo $u$ otro en las obras teatrales tanto de la época colonial, como en aquellas resultantes tras la independencia. Durante el virreinato novohispano ${ }^{19}$ el concepto de lo teatral es bastante amplio. Para ello se tomará la definición de Friedman y Jáuregui, quienes afirman

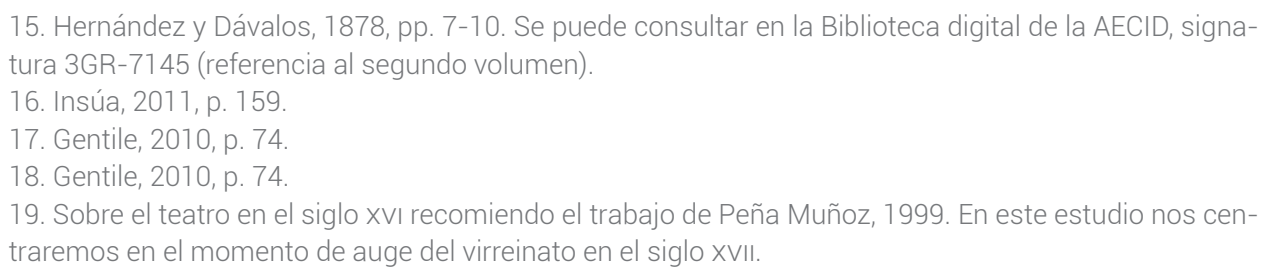


que acudirán a una noción laxa de teatro «sobre la que no aspiramos a un acuerdo crítico» ${ }^{20}$ y se referirán a espacios, discursos y prácticas teatrales ${ }^{21}$. Por lo tanto, podemos considerar como teatro a un conjunto de prácticas diversas. Por ejemplo, pensamos en los espectáculos callejeros o rituales públicos relacionados con el poder civil, en una actividad pedagógica, de propaganda, de instrucción política, la actividad profesional y empresarial, el espacio arquitectónico, etcétera. De lo que no cabe duda es de que nos encontramos con una gran variedad de formas teatrales cuya importancia es indudable en el período colonial22.

Para Arrom ${ }^{23}$, el teatro colonial una vez acabado el asentamiento de los colonos, se puede dividir en dos períodos. Ambos momentos los introduce en el movimiento del Barroco. Las fechas que fija para la clasificación teatral son: 1) 1600-1681 y 2) 1681-1750. El criterio que sigue es el de la calidad de la producción teatral novohispana en relación con la producción en la Península. Veamos con detenimiento esta teoría.

Para él, la producción dramática novohispana del siglo XVII coincide con el florecimiento del teatro peninsular (fechas que coinciden, por cierto, con las fechas de nacimiento y muerte de Calderón, hito teatral indiscutible en el teatro aurisecular). «Pero he aquí que dicha producción, en lugar de ser copiosa y brillante cuando era copiosa y brillante la española, y escasa y opaca cuando entra aquella en su ocaso, resulta precisamente lo contrario» ${ }^{24}$. Esta afirmación parece contradecir a otras fuentes como la de los bibliógrafo ${ }^{25}$ del siglo XIX, quienes reunieron una gran cantidad de producción literaria que se dio durante todo el virreinato. En esta documentación podemos comprobar la abundancia de teatro genuino americano que se produjo a lo largo del período colonial. En cuanto a la calidad de esta producción queda a criterio del estudioso el designarla de esta manera, quien afirma que la escasez de este primer ciclo se debe a que «era tal la calidad y abundancia de las piezas que continuamente llegaban de España, que resultaba un vano esfuerzo todo intento de competencia de parte de los escritores locales» ${ }^{26}$. Sin embargo, el desconocimiento de la mayor parte de la producción dramática novohispana nos permite cuestionar esta afirmación. Por otro lado, también en la Península se gesta una producción literaria que no puede competir con los autores que menciona (Calderón, Tirso de Molina, Lope o Moreto). Por lo tanto, no se puede juzgar la calidad de toda la producción comparándolos con los ejemplos que más destacan en el canon teatral de esta época.

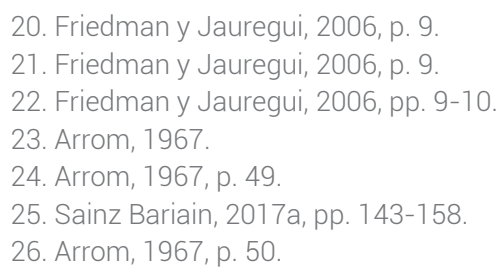


Si, por el contrario, revisamos las definiciones dadas con anterioridad, veremos que el teatro novohispano era muy abundante y cumplía con muchos propósitos. Como apunta Pascual Buxó:

Para los estudiosos de la literatura novohispana es un hecho evidente nuestro limitado conocimiento del caudal de obras escritas entre los siglos XVI y XVIII. Los textos impresos durante el período colonial son apenas una mínima parte de la producción real de los escritores de entonces; salvo Sor Juana Inés de la Cruz o, en algunos aspectos, Matías de Bocanegra y Carlos de Sigüenza y Góngora, las obras más personales de los ingenios novohispanos nunca o casi nunca pudieron publicarse. Concurrían dos causas para ello: los altos precios de impresión y las quisquillosas censuras inquisitoriales ${ }^{27}$.

Por lo tanto, es imposible medir la calidad de la producción teatral ciñéndonos al conocimiento real que tenemos de la amplia literatura de esta época. Parece obvio que muchas de las piezas teatrales que pervivieron fueron aquellas vinculadas a las celebraciones civiles y religiosas. Pascual Buxó afirma que la mayor parte de los libros publicados fueron sufragados por los cabildos civiles o eclesiásticos ${ }^{28}$. Por lo tanto, tenemos a nuestra disposición muchos textos que sirvieron de homenajes para figuras ilustres de la Nueva España (obispos, virreyes, etcétera). Es decir, así como «la gran mayoría de las prácticas teatrales en América ocurren bajo el patrocinio y férula de la Iglesia y las autoridades imperiales» ${ }^{29}$, la producción personal de las figuras ilustres se ha podido perder a lo largo de los siglos. Como señala Pascual Buxó, los bibliógrafos registran una gran nómina de autores y títulos, algunos impresos y otros manuscritos, pero muchos resguardados en bibliotecas de colegios o conventos, depósitos que por las circunstancias históricas del siglo XIX (luchas políticas, la promulgación de las leyes de Reforma) fueron, en muchas ocasiones, destruidos ${ }^{30}$.

Por lo tanto, la teatralidad novohispana registrada parece vinculada a la cultura oficial, civil o religiosa ${ }^{31}$. Piezas teatrales que forman parte de conjuntos festivos, los cuales perduraron durante todo el período colonial. Un ejemplo sería la comedia del jesuita Matías de Bocanegra titulada Comedia de san Francisco de Borja, inserta en todo el conjunto festivo, que los jesuitas ofrecieron al marqués de Villena al llegar a la Ciudad de México ${ }^{32}$. Teatro y fiesta son dos conceptos que en el virreinato aparecían estrechamente unidos al ser abundantes los motivos de celebración, ya que, además de las festividades habituales en la Península, se debe añadir toda aquella fastuosidad relacionada con la figura virreinal. En todo caso, como señala González:

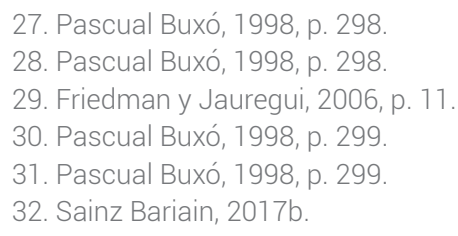


Al estudiar las obras teatrales del Siglo de Oro y en él sus manifestaciones novohispanas, en muchas ocasiones se olvida que se trata, sin importar que sean montajes palaciegos o de corral, de un espectáculo múltiple, que incluye variadas expresiones y géneros y que tiene diversas intenciones ${ }^{33}$.

La intención de la obra depende de las circunstancias que rodean la causa de su producción. Está claro, retomando las definiciones de Friedman y Jáuregui, que en el caso del teatro creado por ocasión de la llegada de los virreyes podía servir para promocionar las virtudes del convento encargado de la celebración o para transmitir un mensaje político al virrey a través del propio texto o gracias a los elementos iconográficos que rodeaban la representación. Además de la obra de Matías de Bocanegra ya mencionada, podemos recordar la Relación del festejo que a los marqueses de las Amarillas les hicieron las Señoras Religiosas del Convento de San Jerónimo en México en 1756, ya en pleno siglo XVIII. Ambos textos nos ofrecen conjuntos festivos dedicados a la figura virreinal y con esa intención de hacer llegar un mensaje al máximo poder civil del virreinato. No olvidemos que este tipo de espectáculo funcionaba como un conjunto festivo formado por varias partes literarias ${ }^{34}$ y también no literarias. Como vemos, lo teatral está muy ligado a los conceptos de fiesta y también de poder, ya que los fastos civiles servían para asentar el poder de la monarquía y, por otro lado, para que los habitantes de la Nueva España se dirigiesen directamente a la figura que ostentaba el poder en el virreinato. Una vez lograda la independencia, esta etiqueta de teatro colonial desaparece, pero no solo es una cuestión de nomenclatura, ya que muchas de las prácticas vigentes en el período también desaparecen.

Por ahora, se ha hecho hincapié en el momento de mayor esplendor para la época colonial, el siglo XVII, aunque hay elementos, como el teatro y su vinculación con las festividades, que se extienden durante toda la época colonial. Sin embargo, para comprender la ruptura que se produce en la configuración del teatro tras la independencia, es necesario abordar cómo era este género durante el siglo XVIII ${ }^{35}$.

Para Peña, el teatro de la Nueva España en este siglo no se puede entender si no pensamos cómo era el teatro peninsular tanto el áureo como el neoclásico ${ }^{36}$. Un teatro que podemos conocer gracias a las colecciones de sueltas que podemos encontrar en la BNE ${ }^{37}$. Se puede apreciar en el teatro dieciochesco cierta proyección del peninsular, pero todavía pervive la representación de los grandes dramaturgos del siglo anterior. No obstante, también hay producción genuina americana, esta vez con una nómina de autores que escribían textos personales y no necesariamente enmarcados en complejos fastos de celebración ${ }^{38}$. Aun así,

33. González, 1999, p. 117.

34. González, 1999, p. 117.

35. Para abordar el teatro novohispano del XVIII recomiendo a Viveros, 1996 y Peña Muñoz, 2006

36. Peña Muñoz, 2006, p. 155.

37. Dato que también recoge Pascual Buxó, 1998, pp. 299-300.

38. Muchos de los autores del Barroco seguían siendo representados, como por ejemplo Calderón, quien fue uno de los predilectos. Las sueltas teatrales que llegaban desde España se sumaban al acervo de autores novohispanos. También se puede conocer una buena nómina de autores en Reyes, 1960, p. 282. 
el neoclasicismo teatral novohispano fue el que, desde el punto de vista del gobierno virreinal, se constituyó en instrumento idóneo para la formación de una conciencia civil en el mexicano de entonces, al que, mediante el teatro, también quería dársele instrucción moral o propia del fuero interior. En efecto, desde el último tercio del siglo XVIII, y con mayor razón durante los inicios del XIX, el teatro era concebido como un taller en donde podían ser labrados los héroes y reformadas las costumbres 39 .

Los virreyes miraban con buenos ojos la actividad teatral que cumplía con la preceptiva neoclásica de Luzán. No en vano, era el propio gobierno virreinal quien permitía y autorizaba las representaciones, para el esparcimiento del pueblo y así ser apartado de la nueva mentalidad política que empezaba a gestarse y que se separaba del poder monárquico ${ }^{40}$. En cualquier caso, la segunda mitad del siglo XVIII puede considerarse como una etapa de renovación y conflicto, «como si los gruesos sillares del mundo colonial comenzaran a resquebrajarse por todas partes y a través de las grietas se precipitaran a chorros el aire y la luz de inusitadas inquietudes» ${ }^{4}$.

\section{EL TEATRO TRAS LA INDEPENDENCIA}

Para González Acosta, el teatro mexicano se encontraba en franca decadencia unos años antes y después de la Independencia, bien por la escasa calidad, bien porque las obras representadas no solían adoptar los temas acuciantes de la realidad nacional42. Por otro lado, Ruiz Bañuls afirma que el panorama teatral del siglo XIX se abre paso entre la reivindicación nacionalista y una sensibilización romántica ${ }^{43}$. Campos Pérez asegura: «Durante los dos primeros años de ocupación francesa de la Península y hasta el inicio de la insurgencia en México en septiembre de 1810, del conjunto de obras que se recibieron, las que se escenificaron en los teatros principales de la ciudad de México fueron fundamentalmente aquellas relacionadas con temas patrióticos» ${ }^{44}$ - un ejemplo sería la representación en mayo de 1810 del drama patriótico La fiereza de Inglaterra y embarque en el norte de las tropas españolas al mando del Excmo. Señor marqués de la Romana ${ }^{45}$. Sin embargo, Schmidhuber apela a que, a pesar de la Independencia que puso fin al imperio colonial, el teatro no se desligó de la tradición peninsular.

Al cabo de las guerras de independencia de México que pusieron fin al imperio colonial español, el teatro no se desligó de la tradición peninsular, como lo comprueban las obras dramáticas de José Joaquín Fernández de Lizardi (1776-1827)

39. Viveros, 1996, p. 17.

40. Viveros, 1996, p. 19. Las representaciones que servían para tal esparcimiento serían entremeses, sainetes, tonadillas o loas (Viveros, 1996, p. 19).

41. Arrom, 1967, p. 115

42. González Acosta, 2010, p. 148.

43. Ruiz Bañuls, 2004, p. 208.

44. Campos Pérez, 2012, p. 230.

45. Dato que tomo de Campos Pérez, 2012, p. 231. 
y el triunfo escénico en la madre patria de Manuel Eduardo de Gorostiza (17891851); las comedias de este último parecen «escritas para un auditorio español, sin que en parte alguna se trasluzca la oriundez americana del poeta», como lo afirma Menéndez Pelayo (Historia: 108-109). Históricamente la obra de Manuel Eduardo de Gorostiza constituye un puente entre el teatro de Leandro Fernández de Moratín y el de Manuel Bretón de los Herreros, ambos peninsulares ${ }^{46}$.

De hecho, asegura que el romanticismo mexicano se sirvió de la influencia del español y del francés ${ }^{47}$. También González Acosta afirma que el teatro mexicano en los primeros años del siglo XIX se encaminó por los rumbos del costumbrismo ${ }^{48}$. Todas estas propuestas significan la complejidad del teatro mexicano ya en plena independencia. La búsqueda de nuevos héroes, el decantarse por temas patrios o no, asumir modelos extranjeros o preferir crear géneros teatrales propios son aspectos que intentaremos reflejar a continuación.

Continuamos de la mano de González Acosta, ya que ilustra cómo comenzó el teatro decimonónico tras la independencia. Afirmaba que en los primeros años del siglo XIX la producción dramática se podía considerar como un teatro costumbrista, «aunque no es sino hasta Francisco Luis Ortega cuando puede hablarse propiamente de un teatro costumbrista. Este autor compuso la obra alegórica México libre [...], que puede asumirse como la fundadora del teatro del México independiente» ${ }^{49}$. Si bien el teatro no estuvo ajeno a la Independencia, es evidente que la tumultuosa vida política del México del siglo XIX y más tarde también, no favorecía el pleno desarrollo de la actividad teatral, por lo que la relación entre teatro y poder sigue estando vigente, aunque con parámetros muy distintos a los coloniales, donde el poder se reflejaba a través de los grandes fastos encabezados por piezas teatrales. Para Campos Pérez, el teatro evolucionó desde ese estadio patriótico antes de la emancipación, hacia un teatro más político durante los primeros meses tras la independencia «a medida que la situación política en el país se fue haciendo más agitada y compleja - debido, sobre todo, a las disputas entre monárquicos y republicanos, y dentro de estos últimos entre federalistas y centralistas-el teatro político comenzó a ocupar un lugar en las carteleras» ${ }^{50}$. Un ejemplo de pieza teatral de estas características sería Roma libre, publicada en 1823 en el Coliseo de la Ciudad de México, «con la que los partidarios del republicanismo festejaban el advenimiento del nuevo régimen» 51

Uno de los temas que marcan un cambio de mentalidad entre el virreinato y la nueva etapa independiente es la búsqueda de los propios héroes. En el teatro colonial de circunstancia, el héroe se centra en las figuras políticas de la monarquía hispánica. La intención de permanencia del poder sobre el territorio gesta un sistema iconográfico vinculado a la monarquía que queda reflejado en los fastos

51. Campos Pérez, 2012, p. 233. Los datos sobre la obra de teatro Roma libre se toman de este trabajo. 
dedicados a sus representantes en América. Este aspecto se aprecia sobre todo en las obras dedicadas a los recibimientos de los virreyes, pero también con las figuras representantes del poder eclesiástico. El siglo XIX vuelve la mirada a su pasado y busca héroes precolombinos, así como reescribe la historia de la conquista ${ }^{52}$. La presencia de la historia en la literatura se relaciona de forma estrecha con la búsqueda de la identidad53:

Si bien los orígenes mismos de la creación literaria hispanoamericana pueden situarse en la plasmación de una materia histórica -la que configura el amplio corpus textual que definimos como Crónica de Indias-, lo cierto es que los procesos de Independencia y, sobre todo, de formación de las nuevas naciones intensificaron la presencia de la historia en dicha creación literaria, esto es, la reflexión sobre un pasado que pudiera -como ha apuntado Noé Jitrik- «esclarecer el enigma del presente» 54 .

Así lo entiende también Ruiz Bañuls, quien cree que la dramaturgia cuya temática se centra en personajes prehispánicos «resulta ser una característica esencial para comprender el perfil del teatro en México»55. Hay que tener en cuenta que en el siglo XIX se viven las luchas entre conservadores y liberales y la percepción que cada grupo tiene de lo indígena ${ }^{56}$. Como señala la autora, se trata de: «Un periodo en el que los autores teatrales, impulsados por un espíritu nacionalista, vuelven la mirada hacia la historia antigua de México y encuentran en los reyes y príncipes aztecas la inspiración para expresar su patriotismo» ${ }^{57}$.

Si de la primera parte del siglo se puede afirmar que la escena mexicana está dominada por fuerte presencia de dramas románticos, muchos de ellos de procedencia extranjera (como también señalaba Schmidhuber), la segunda parte lucha por una literatura originalmente mexicana y se estrenaron unas cuarenta y tres obras de autores mexicanos ${ }^{58}$. De todo ello es testigo la prensa del momento. Se comentaba en el primer epígrafe de este trabajo el papel que tuvo la prensa en todo el proceso de independencia y gran parte del éxito de este teatro se vio reflejado en ella. «El auge que cobró el teatro en el siglo XIX como expresión artística y espacio de socialización e intercambio cultural dejó una huella indeleble en la producción periodística mexicana de esa centuria ${ }^{59}$. Hubo un interés creciente por parte de los intelectuales por escribir reseñas de los espectáculos, por lo que la prensa dedicó

52. González Acosta publicó en 2017 tres dramas rescatados de este período histórico que demuestran este interés por los héroes del pasado. Estas obras Ilevan por título: Xicoténcatl. Comedia heroica en cuatro actos, de José María Mangino; Xiconténcatl. Tragedia en cinco actos, de José María Moreno Buenvecino y La Teutila, tragedia en cinco actos, de Ignacio Torres Arroyo.

53. Aracil Varón, 2007, p. 5.

54. Aracil Varón, 2007, p. 5.

55. Ruiz Bañuls, 2004, p. 208

56. Ruiz Bañuls, 2004, p. 208. Pensamiento que depende también de las ideas románticas.

57. Ruiz Bañuls, 2004, p. 209

58. Ruiz Bañuls, 2004, p. 209

59. Moreno Gamboa, 2006, p. 209. En este trabajo deja muestras de la compleja labor que supone la recuperación de muchas de las obras de este período por encontrarse en malas condiciones para su edición. 
un espacio específico al teatro. Moreno Gamboa ofrece un listado de quince títulos especializados en reseñas del teatro de la época ${ }^{60}$. Es interesante porque refleja el interés del público y de los intelectuales por la dramaturgia. Este desarrollo de la prensa dedicada a los espectáculos tuvo su auge en las últimas décadas del siglo; entre 1870 y 1880.

Como conclusión, se apunta a la necesidad de ahondar en el conocimiento real de la producción dramática a lo largo de los siglos. Pero, sobre todo, cabe destacar la necesidad de recuperar más autores de la transición entre el siglo XVIII y el siguiente. Rescatar qué ocurrió una vez lograda la Independencia y cómo afecta a la cultura mexicana, ya que su repercusión sigue vigente en la actualidad. La identidad es un aspecto de honda importancia en la cultura de un país y el pasado es la llave para comprender nuestro presente. Muchas de las opiniones sobre la calidad del teatro novohispano o del teatro tras la Independencia son fruto de prejuicios infundados por los ideales políticos de diversas épocas. Sin embargo, la labor del investigador lleva ya muchas décadas intentando recuperar el sentido real de cada producción literaria dentro del marco en el que se insertan. Debemos comprender los entresijos socioculturales que mueven la cultura de cada época y analizar la calidad respecto a parámetros filológicos.

\section{Bibliografía}

Aracil Varón, Beatriz, «En torno al personaje histórico. Figuras precolombinas y coloniales en la literatura hispanoamericana de la Independencia a nuestros días», América sin nombre, 9-10, 2007, pp. 5-6.

Arrom, José Juan, Historia del teatro hispanoamericano. Época colonial, México, Ediciones de Andrea, 1967.

Barruchi y Arana, Joaquín, Relación del festejo que a los Marqueses de las AmariIlas les hicieron las Señoras Religiosas del Convento de San Jerónimo, México, 1756, ed. Frederick Luciani, Madrid / Frankfurt am Main, Iberoamericana / Vervuert, 2011.

Bernal Ruiz, Graciela, «Españoles y americanos en la guerra de la independencia mexicana, ¿momento de saldar cuentas?», Catharum. Revista de Ciencias y Humanidades, 8, 2007, pp. 7-14.

Campos Pérez, Lara, «"La escuela más enérgica del pueblo". La circulación de un ideario liberal entre España y México a través de actores y obras de teatro durante el primer tercio del siglo XIX», Ariadna histórica. Lenguajes, conceptos, metáforas, 1, 2012, pp. 221-241.

60. Moreno Gamboa, 2006, p. 210. Añade que una búsqueda más exhaustiva probablemente incluiría más títulos. A pesar de ello, el estudio de estos quince títulos arroja luz sobre el conocimiento del teatro decimonónico en México. 
Franco, Jean, «En espera de una burguesía: la formación de la intelligentsia mexicana en la época de la Independencia», en Actas del VIII Congreso de la Asociación Internacional de Hispanistas, coord. A. David Kossof, Ruth H. Kossof, Geoffrey Ribbans, José Amor y Vázquez, Madrid, Istmo, 1986, vol. 1, pp. 21-36.

Friedman, Edward H., y Jáuregui, Carlos, «Teatro colonial hispánico. Introducción», Bulletin of the Comediantes, 58, 1, 2006, pp. 9-30.

Gentile, María Beatriz, «Insurrección y lealtad en la independencia de México: la prensa y la "guerra de palabras"», Anuario del Centro de Estudios Históricos «Prof. Carlos S. A. Segreti», 10, 2010, pp. 73-89.

González, Aurelio, «Construcción teatral del festejo barroco: Los empeños de una casa de sor Juana», Anales de literatura española, 13, 1999, pp. 117-126.

González Acosta, Alejandro, «Se levanta el telón: señoras y señores, ila Independencia!», Boletín del IIB, 15, 1-2, 2010, pp. 147-151.

González Acosta, Alejandro, Teatro republicano de México. Tres dramas rescatados del México independiente, México, UNAM, 2017.

Gruzinski, Serge, La ciudad de México: una historia, México, Fondo de Cultura Económica, 2008.

Hernández y Dávalos, Julia Elena, Colección de documentos para la historia de la guerra de independencia de México. De 1808 a 1821, México, José María Sandoval, Impresor, 1878.

Insúa, Mariela, «El retrato del periodista en la obra de José Joaquín Fernández de Lizardi», Alpha, 33, 2011, pp. 159-170.

Landavazo, Marco Antonio, «Guerra y violencia durante la revolución de independencia de México», Revista de Estudios Históricos, 48, 2008, pp. 15-40.

Moreno Gamboa, Olivia, «Panorama de la prensa teatral en la ciudad de México (siglo XIX)», Boletín del IIB, 9, 1-2, 2006, pp. 209-225.

Ortiz, Fernando, «Del fenómeno social de la transculturación y su importancia en Cuba», en Contrapunto cubano al tabaco y el azúcar, La Habana, Editorial de Ciencias Sociales, 1983, pp. 86-90.

Ortiz Escamilla, Juan, El teatro de la guerra: Veracruz, 1750-1825, Castelló de la Plana, Publicacions de la Universitat Jaume I, 2008.

Pascual Buxó, José, «Una defensa novohispana del teatro», Calíope. Journal of the Society for Renaissance and Baroque Hispanic Society, 4, 1-2, 1998, pp. 298-310.

Peña Muñoz, Margarita, «Proyección del teatro áureo en el teatro de la Nueva España», Anuario de Letras: lingüística y filología, 37, 1999, pp. 197-224.

Peña Muñoz, Margarita, «El teatro novohispano en el siglo XVIII», Bulletin of the Comediantes, 58, 1, 2006, pp. 155-172. 
Reyes, Alfonso, Obras completas XII: Grata compañía; Pasado inmediato; Letras de la Nueva España, México, Fondo de Cultura Económica, 1960.

Ruiz Bañuls, Mónica, «Cortés y otros héroes de la conquista en el teatro mexicano del siglo XIX», América sin nombre, 5-6, 2004, pp. 208-215.

Sainz Bariain, Isabel, «Corpus de bibliógrafos para el estudio de autores novohispanos», en Corpus y bases de datos para la investigación en literatura, ed. Rebeca Lázaro Niso, Logroño, Fundación San Millán de la Cogolla, 2017a, pp. 143-158.

Sainz Bariain, Isabel, Poder, fasto y teatro: la «Comedia de san Francisco de Borja» (1640), de Matías de Bocanegra, en su contexto festivo, Alicante, Universitat d'Alacant, 2017b.

Schmidhuber, Guillermo, Dramaturgia mexicana: fundación y herencia, Alicante, Biblioteca Virtual Miguel de Cervantes, 2014.

Viveros, Germán, Talía novohispana: espectáculos, temas y textos teatrales dieciochescos, México, UNAM, 1996. 